\title{
Exploration and Practice of Constructing the Network Classes of Transportation and Packaging Courses Under the Epidemic
}

\begin{abstract}
Lijun Zhou*
Nanjing Vocational University of Industry Technology

*Corresponding author. Email: 2004100392@niit.edu.cn

ABSTRACT

With the development of information technology, the online classroom has a long history, but it has been used as a supplement to the traditional classroom for a long time, and the advantages of the online classroom have not been fully utilized. With the outbreak of novel coronavirus pneumonia (COVID-19), online classrooms have become the main method of classroom teaching. This article introduces the concept of online classroom, analyzes the problems of lack of teaching resources, difficult control of students' learning status, and lack of emotional communication between teachers and students, and focuses on the analysis of four aspects of online classroom construction strategies. With the change of students' study habits, there are still huge opportunities for development in the online classroom after the epidemic, and it plays an increasingly important role in teaching.
\end{abstract}

Keywords: Novel Coronary Pneumonia, Online Classroom, Transport and package.

\section{INTRODUCTION}

The outbreak of the COVID-19 in 2020 severely threatened the lives and health of the people and greatly affected the normal teaching work. All provinces have delayed schools in accordance with the Law of the People's Republic of China on Emergency Response and the Law of the People 's Republic of China on the Prevention and Control of Communicable Diseases and the relevant local public health emergency response mechanisms. As of the end of April, there are still many primary and secondary schools that have not resumed school. In order to reduce the loss of delayed start of the school, the school has launched a variety of online classrooms, such as China University MOOC, Tencent Classroom, QQ Group Classroom, Smart Vocational Education, and Dingding Live Broadcast. Through the online classroom, traditional teaching classes can be basically realized Pre-preview, classroom attendance, group discussion, teaching interaction, after-class question answering, homework completion, classroom testing and exams, etc.

\section{RE-EXAMINE THE ONLINE CLASSROOM}

As of now, there is no clear definition for online classrooms. This article believes that online classroom refers to the integration of learning resources and learning tools based on the Internet platform that enables teachers and students to share a variety of resources. Learning resources refer to anything that helps learners to learn effectively. They can be places where learning activities are carried out, media resources and interpersonal relationships. This article mainly refers to media resources; Knowledge management tools, reading tools, and communication and collaboration tools.

The online classroom has the following characteristics:

\subsection{Diversification of Course Resources}

Online courses have changed the rigid and scarce resources of traditional courses. It provides a wide variety of resources in various forms such as text, audio, animation, video, literature, website links, simulation experiments, and live online broadcasts of companies. Different types of resources can be re-edited as needed 
to generate curriculum resources that combine dynamics and statics, complement each other with reality, and integrate theory with reality.

\subsection{Three-dimensional Learning Activities}

With the help of the network platform, communication between classmates and classmates, and between classmates and teachers is more convenient, and $24 \times 7$ communication can be achieved. Before the class, the teacher publishes teaching tasks, provides preview cases, audio and video materials, and electronic textbooks on the online platform. The students discuss with each other and find problems. They can communicate with the teacher online in time, or they can communicate with the teacher during the class. In the class, teachers complete the teaching through various methods such as network platforms, online video, and QQ groups. After class, teachers will answer questions through the platform, complete the test and evaluate the teaching effect.

\subsection{Visualization of Teaching Effect}

In traditional teaching, due to the lack of auxiliary tools and the limitation of teachers' ability, the teaching effect is difficult to measure quantitatively, and the teaching content and teaching methods lack pertinence. Under the network platform, not only can the homework be corrected automatically, but also the students' homework, online Q\&A, and error points in the exam can be statistically analyzed, and related knowledge points can be linked to the teacher in the form of a friendly interface. In response to missing points, teachers should adjust the teaching content in time, teach students in accordance with their aptitude, and be targeted

\section{DIFFICULTIES IN CONSTRUCTING ONLINE CLASSROOM}

Online classrooms use platforms and other tools to complete teaching tasks, which are quite different from traditional classrooms. The construction of online classrooms has the following difficulties.

\subsection{Lack of Teaching Resources}

There are many types of online classroom resources. The production of resources such as videos, animations, and cases requires high technology and strong funds. Most teachers do not have these conditions and cannot be completed by relying on teachers alone. . Moreover, the "transportation and packaging" course involves facilities and equipment in the field of transportation and packaging, as well as information technology. The content is updated quickly and teaching resources need to be constantly updated. In order to solve the lack of teaching resources, it is possible to organize teaching teams across disciplines, self-made some cases, simple animations, and experimental projects. Teachers can also cooperate with industry enterprises to learn from each other's strengths and jointly produce more complex teaching resources.

\subsection{Students' Learning Status is Difficult to Control}

In online classrooms, teachers and students complete their teaching through the Internet. Visual monitoring, targeted questioning, and many other teaching monitoring methods in traditional classrooms are useless. In many cases, online classrooms involve the teacher alone in the classroom. In order for students to follow the rhythm of the classroom, the content and methods of teaching must be quite different from those of traditional classrooms, which puts forward new requirements for teachers, not only having the ability to produce curriculum resources, the ability to apply information technology and The ability of procedural assessment in the classroom and the ability of artistic teaching in online classrooms are also required.

\subsection{Lack of Emotional Communication between Teachers and Students}

Emotional communication is indispensable in teaching activities and teacher-student interactions. The spiritual impact, emotional blending and echoing between teachers and students in education are not only reflected in the cognitive process, but also in the process of emotional communication. In traditional teaching, every move of a teacher, an eye look, a smile, and an encouragement can resonate with students, which produce chemical reactions, make students have a pleasant psychological experience, and stimulate students' initiative and enthusiasm for learning. In the course of "Transportation and Packaging", "Packaging Marking" was taught by analyzing the investigation report of the "7.12" major explosion and fire accident of Yibin Hengda Technology Co., Ltd., explaining the importance of using packaging markings in accordance with national standards. The rich body's language gives students a deep impression and achieves good teaching results. However, the indirect contact of online classrooms blocks the emotional communication between teachers and students, which also puts forward higher requirements for the design of online classrooms.

\section{CONSTRUCTION STRATEGY OF ONLINE CLASSROOM}

Teachers and students teach face-to-face in traditional classrooms to complete all teaching tasks in one space. Online classroom is remote teaching different from traditional classroom, which uses the network platform to complete the teaching goal. The 
construction of online classroom involves four core elements of teaching resources, teaching methods, teaching evaluation and teaching process. They constitute the ecology of the online classroom.

\subsection{Integrate Various Teaching Resources}

In traditional teaching, teachers are the core and most important resource. Different teachers have different teaching effects in the same course. In online courses, teachers can use a variety of course resource packages, network resources, and digital resources built by teamwork. Teachers can also make full use of the fragmented time of students to improve the enthusiasm and initiative of learning. At present, the main types of teaching resources for online courses mainly include documents, audio, video, case studies, enterprise online live broadcasts, micro-classes, exercise libraries, and rich media. In the "Transportation Mode" chapter of the "Transportation and Packaging" course, the distribution network of my country's highways, the map of China's river system, the map of China's railway traffic and other materials will be uploaded to the vocational education cloud platform before class, and assign the pre-class task "Analyze the relationship between my country's traffic flow and the economy". Turn on the playback function of Tencent Classroom during class for students to look back when they need it after class. Turn on the playback function of Tencent Classroom during class, so that students can look back when they need it after class. Use road transport operation video, port operation video, railway transportation operation video and airport operation video as after class to consolidate the knowledge learned in the unit, and assign unit online tests and group discussions.

\subsection{Flexible Use of Multiple Teaching Methods}

According to the survey, the average time for British university students to concentrate on listening to lectures is only 10 minutes. Because traditional classroom teaching is led by teachers and can control the order of the classroom, 90 minutes of teaching can also achieve good results. In online classrooms, teachers and students are connected through the network. During the course, it is difficult to understand the students' learning conditions in time. The traditional teaching methods taught by teachers must be changed, and the core knowledge points of the teaching content must be extracted, and are presented in different forms through micro-classes, animation, Video, case studies, experiments, and company site online. The attention of students is concentrated by frequently using questions, group discussions, and students' explanations. In the "Storage and Transportation Packaging Technology and Methods" section, it is divided into four small items: cushion packaging and its test, moisture-proof packaging and its test, mold-proof packaging and its test, and rust-proof packaging and its test. In "Cushion Packaging and Its Experiments", students will first learn about the principles, materials and technology of cushion packaging through a 10-minute micro-class video, share relevant pictures through QQ group, and then discuss examples of cushion packaging in daily life in a group. The group analyzes the principle, the team members report the results together, and verify the effect of the cushion packaging through the cushion test, and finally complete the quiz online and analyze the test results. It is ensured that the duration of one teaching method does not exceed ten minutes, and different teaching methods are used alternately to ensure the effect of online course teaching.

\subsection{Carrying out All-round Teaching Evaluation}

Online courses provide more timely and comprehensive teaching evaluation than traditional courses. The evaluation of traditional courses is based on summative evaluation and payed more attention to the results of teaching. Online teaching has the characteristics of convenience, real-time and intelligence. Through the real-time monitoring of the entire learning process through the network, the effects of learning can be fully understood from the grasp of knowledge, skill training, learning attitude and professionalism. Through real-time data processing, existing problems are discovered in time, and students are reminded to adjust the progress, methods or strategies of learning in response to problems that arise, and teachers can be asked to solve them when necessary. In the teaching process, the process evaluation is regularly implemented from different angles in the form of tests, assignments, questions, works display, group discussions, group reports, and questionnaires. There are not only self-evaluations, mutual evaluations, teacher evaluations, but also group evaluations to control students' learning status in time.

\subsection{Reconstruct the Entire Teaching Process}

The teaching process consists of three links before class, during class, and after class. The pre-class link is the prelude to the mid-class link to prepare for the class. The teaching PPT of this chapter, recorded packaging micro-videos, simple objective pre-tests, and video links to video websites are released before class for students to preview. Teachers analyze the learning situation through platform, understand the weaknesses of learning, and formulate teaching plans accordingly. Classes are taught in accordance with the proposed teaching plan, and this stage focuses on the concentration and enthusiasm of students in learning. Because online classrooms are distance teaching, students' learning status cannot be directly observed through vision. In teaching, more interactive forms such 
as communication, discussion, question and answer, and collaborative inquiry are needed to avoid teachers' lectures. The after-class links are mainly to check the missing parts and targeted guidance. The teacher pushes the corresponding learning materials for different learning effects in accordance with students' learning according to the pre-class links and the links in the class. Students can also self-test and find weaknesses Link, search for materials in the course resource library, or ask classmates and teachers for help online.

\section{CONCLUSION}

Before the outbreak of the epidemic, traditional classrooms were the mainstay, and online classrooms were supplemented by online classrooms. After the outbreak, the organic combination of online classrooms and traditional classrooms has basically been realized. They complement each other and have achieved good teaching results.

\section{ACKNOWLEDGMENTS}

This paper is supported by a grant from Research Projects of Higher Education Reform in Jiangsu Province (No.2019JSJG479).

\section{REFERENCES}

[1] Tang Yewei1, Pang Jingwen1, Zhong Shaochun1,2, Wang wei1,Under the Information Technology Environment Wisdom Classroom Building Method and Case Study, China Educational Technology[J],2014,334(11):23-29

[2] Xie You-ru, Research on the Construction Model of Collaborative Knowledge in Network Classroom[D], Doctoral Dissertation of Southwest University, 2009,(5):5

[3] Liu Jie, Zhou Yu-xia, Xie Ji-li, Analysis and Countermeasures of Emotional Communication Problems Between Teachers and Students in Live Broadcasting Distance Classroom, Journal of Chuxiong Normal University, 2014, 29 (12): 56-61

[4] http://sc.people.com.cn/n2/2019/0214/c34516732634918.html, 2019, 2.Investigation Report on '7 - 12'Major Explosion Fire Accident of Yibin Hengda Technology Co., Ltd., People.cn, http://sc.people.com.cn/n2/2019/0214/c34516732634918.html, 2019, 2

[5] Ti Yan, Rich Media Wisdom Textbook---- Ondemand publishing in the field of textbooks for junior colleges[J], Digital printing, 2017(3):41-42

[6] $\mathrm{Hu}$ Xiao-yong, Zhu Long, Feng Zhi-hui, Zheng Xiao-dan, The Development of ICT-Based Instructional Models and Methods:Trends and
Directions, E-Education Research[J], 2016, 278(6):12-1 